\title{
Geospatial Analyses of Thyroid Cancer Incidence in Kelantan, Malaysia
}

\author{
Zuhdi, N. F. M., ${ }^{1}$ Rahman, W. F. W. A., ${ }^{1 *}$ Damitri, T. A., ${ }^{2}$ Ismail, A. F., ${ }^{3}$ Hassan, R. ${ }^{4}$ \\ ${ }^{1}$ Department of Pathology, School of Medical Sciences, Universiti Sains Malaysia, 16150, Kubang Kerian, \\ Kelantan, Malaysia, E-mail: fatihahzuhdi39@gmail.com,wfaiziah@usm.my* \\ ${ }^{2}$ Department of Chemical Pathology, School of Medical Sciences, Universiti Sains Malaysia, 16150, Kubang \\ Kerian, Kelantan, Malaysia, E-mail: damitri@usm.my \\ ${ }^{3}$ Department of Community Medicine, School of Medical Sciences, Universiti Sains Malaysia, 16150, \\ Kubang Kerian, Kelantan, Malaysia, E-mail: afilza@usm.my \\ ${ }^{4}$ Department of Hematology, School of Medical Sciences, Universiti Sains Malaysia, 16150, Kubang Kerian, \\ Kelantan, Malaysia, E-mail: roslin@usm.my \\ *Corresponding author \\ DOI: https://doi.org/10.52939/ijg.v17i5.2023
}

\begin{abstract}
Geographical Information System (GIS) has been widely used in evaluating health data. GIS-based disease mapping can act as a tool for an effective form of communication in public health and planning disease surveillance strategies. Yet, there is limited data on spatial distribution of cancer in Malaysia. In the present study, GIS was employed to map the thyroid cancer incidences, analyse the spatial distribution of the cases and assess their geographical accessibility to public hospitals. Registries of patients diagnosed with thyroid carcinoma from the year of 2013 to 2020 were retrieved and information regarding the year of diagnosis, age, gender, residential addresses and histological subtypes were obtained. The coordinates of residential addresses and public hospitals were obtained using Global Positioning System (GPS) and the radius of public hospitals were set within and beyond $10 \mathrm{~km}$. Then, all data were inserted into ArcGIS 10.2 software and spatial analysis was performed. A total of 90 cases with thyroid carcinomas were recorded and mapped. The spatial distribution of thyroid cancer cases in Kelantan represented a clustered pattern (NNR: 0.549377, pvalue $<0.001)$ with most cases concentrated at northern part of Kelantan. Buffer analysis revealed that most of the cases (60\%, 54 cases) were located within $10 \mathrm{~km}$ radius from public hospitals and the remaining 36 cases (40\%) were situated beyond $10 \mathrm{~km}$ radius from public hospitals. In conclusion, thyroid cancer cases in Hospital USM were clustered with most cases concentrated at the northern part of the state. Majority of the cases have a good geographical access to public hospitals. These study findings provide useful information for health practitioners in planning public health intervention by targeting locations with poor geographical access to health facilities in order to improve overall health population in Kelantan.
\end{abstract}

\section{Introduction}

Thyroid cancer is one of the most common endocrine malignancies (Horner et al., 2009), representing $2 \%$ of all cancers with approximately 2 fold of incidence rate in the past 25 years (Goodarzi et al., 2018). It is one of the rapid growing types among all cancers worldwide (Jung et al., 2012). Asia continent recorded the highest incidence with $349,897(59.7 \%)$ cases out of 586,202 new cases and highest mortality rates with 25,668 (58.8\%) cases out of 43,646 cases recorded worldwide (Globocan, 2020). A rapid surge in the incidence rate of thyroid cancer has been reported in the past several decades in many countries (Kilfoy et al., 2009, Enewold et al., 2009, Liu et al., 2001 and Reynolds et al., 2005). Northern European countries, Australia and Japan experienced a relatively low incidence and a little increase (La Vecchia et al., 2015 and Franceschi and Vaccarella, 2015) whereas steep upward trends of thyroid cancer were observed in southern European countries (Busco et al., 2013 and Colonna et al., 2015), the United States (Davies and Welch., 2006, 2014 and Chen et al., 2009) and most markedly in the Republic of Korea (Ahn et al., 2014). In China, a strong increase in the incidence was also reported by previous studies (Du et al., 2014, Xie et al., 2012; Xie et al., 2014). This rapid increase has caused widespread public concern about thyroid cancer. In Malaysia, thyroid cancer ranked eighth most frequent cancer among female in Malaysia with age 
standardized rate of 3.2 per 100,000 population between 2012-2016 (Azizah et al., 2019). In Kelantan state, thyroid cancer is the fourth common cancer and recorded much higher age-standardized rate $(5.1 \%)$ than the national average (Othman et al., 2008). A recent study highlighted that thyroid cancer incidence in Kelantan is at an alarming rate, with annual cases increment of approximately $2.7 \%$ over 10-year period from 2006 to 2015.

Incorporating spatial information in cancer data can examine the occurrence of cancer incidence in relation to the geographic variation and environmental parameters (Wang et al., 2008 and Levine et al., 2009). These spatial components can track new cases as well as demonstrate the geographic distribution, location and pattern of cases (Moore and Carpenter, 1999 and Rushton et al., 2006). However, the data kept by National Cancer Registries are in the tabular form which only provides the statistical data of the cases. The spatial data can be integrated into the existing tabular data by using Global positioning system (GPS) to include the geographical location based on the addresses of patients (Wang et al., 2008) which will be mapped using Geographical Information System (GIS) software.

Emergence of GIS as a great tool in geospatial technology is becoming more prominent in healthcare implementation (Musa et al., 2013). Spatial data analysis using Geographic Information System (GIS) is increasingly being used to determine the cluster of cases, identify disease pattern and evaluate the environmental and socioeconomic factors on the geographical distribution of disease (Hanley et al., 2015). It is also used to analyse the accessibility to public health facilities (Kuupiel et al., 2019). GIS-based disease mapping act as a tool for an effective form of communication in public health and planning disease surveillance strategies (Samat et al., 2013). Many studies have applied GIS technology and spatial data analysis in assessing health data (Levine et al., 2009 and Rushton et al., 2006). In western countries, data retrieved from the cancer registry can be utilized to relate the cancer incidences with geographical and demographic factors (Higgs et al., 2005 and More and Carpenter, 1999).

Currently, the diagnosis and management of thyroid cancer in Malaysia is good, owing to a number of guidelines that have been recently proposed. However, the thyroid cancer incidences in Malaysia are increasing in trend and patients still present with advanced stage of disease. Within the period of 2007-2011 and 2012-2016, there is an increment of 650 thyroid cancer cases recorded and male patients are more commonly observed with stage III and IV of the disease with $58.3 \%$ in 2012 2016 (Azizah et al., 2019). This is due to the risk factors of thyroid cancers that may vary accross different populations and geographical area. Since thyroid cancer has also been linked to environmental factors, the use of spatial techniques in determining the relationship will give a new pespective into this issue. The commonly used spatial techniques for health research include disease mapping, distance calculations, spatial aggregation, clustering, spatial smoothing, and spatial regression (Tsai, 2012 and Scott et al., 2002). However, there is limited data on spatial distribution of cancer in Malaysia. Hence, in this study, we aim to investigate the spatial distribution of thyroid cancer cases in Kelantan state and to determine whether there are associations with the geographical accessibility to public hospitals. This will contribute to better planning of health care services and programs to the community in order to improve the overall health population.

\section{Material and Method}

\subsection{Study Design and Study Population}

This is a retrospective study, covered all thyroid cancer patients between the periods of 2013 to 2020 in Hospital Univeriti Sains Malaysia (USM). Hospital USM is a referral centre for thyroid cancer management. Patients with confirmed histopathologic diagnosis of thyroid carcinoma were included. Information regarding the year of diagnosis, age, gender, and residential addresses were extracted from the patients registries in medical record office. These registries were carefully examined to ensure no duplicate entry. The histological subtypes of cancers were obtained from histopathological report in Pathology Department. A total of 90 cases with complete data were included in this study.

\subsection{Study Location}

This study involved 15 districts, including 9 districts from Kelantan and 6 districts from Terengganu, near the Kelantan's border. The districts involved in Kelantan are Kota Bharu, Bachok, Pasir Mas, Pasir Puteh, Machang, Tumpat, Tanah Merah, Kuala Krai and Gua Musang. Whereas, the districts from Terengganu are Besut, Kuala Terengganu, Kemaman, Setiu, Kuala Nerus and Marang. A total of 9 public hospitals involved in this study, which are Hospital Gua Musang, Hospital Kuala Krai, Hospital Tengku Anis, Hospital Machang, Hospital Tanah Merah, Hospital Pasir Mas, Hospital Universiti Sains Malaysia, Hospital Raja Perempuan Zainab II and Hospital Tumpat. The addresses of these public hospitals in Kelantan were obtained 
from Kelantan Health Department. All data obtained were recorded in Microsoft Excel format.

\subsection{Spatial Analysis}

The analysis of spatial data was performed using ArcGIS 10.2 software. Prior to analysis, the geographic coordinates of residential addresses and public hospitals in Kelantan were obtained using Global Positioning System (GPS). The Spatial global pattern analysis by average nearest neighbour ratio was carried out to determine the spatial distribution of thyroid cancer cases. The Average Nearest Neighbor tool measures the distance between each feature centroid and its nearest neighbor's centroid location. It then averages all these nearest neighbor distances. If the average distance is less than the average for a hypothetical random distribution, the distribution of the features being analyzed is considered clustered. If the average distance is greater than a hypothetical random distribution, the features are considered dispersed. The average nearest neighbor ratio is calculated as the observed average distance divided by the expected average distance (with expected average distance being based on a hypothetical random distribution with the same number of features covering the same total area).

The Average Nearest Neighbor ratio is given as:

$$
\mathrm{ANN}=\frac{D_{O}}{D_{E}} \quad \text { Equation } 1
$$

where $D_{O}$ is the observed mean distance between each feature and its nearest neighbor:

$$
D_{O}=\frac{\sum_{i=1}^{n} d_{i}}{n} \quad \text { Equation } 2
$$

and $D_{E}$ is the expected mean distance for the features given in a random pattern:

$$
D_{E}=\frac{0.5}{\sqrt{n / A}}
$$

Equation 3

In the above equations, $d_{i}$ equals the distance between feature $i$ and it's nearest neighboring feature, $n$ corresponds to the total number of features, and $A$ is the area of a minimum enclosing rectangle around all features, or it's a user-specified Area value.

The average nearest neighbor z-score for the statistic is calculated as:

$$
z=\frac{D_{O}-D_{E}}{S E} \quad \text { Equation } 4
$$

where:

$$
S E=\frac{0.26136}{\sqrt{n^{2} / A}} \quad \text { Eqaution } 5
$$

\section{Results}

\subsection{Geographical Distribution of Thyroid Cancer Cases}

Figure 1 showed the geographical location mapping of all thyroid cancer cases from 2013 to 2020 in Hospital USM $(n=90)$. Thyroid cancer cases were distributed throughout the state with high concentration in the northern part of Kelantan.

\subsection{Spatial Distribution of Thyroid Cancer Cases}

Spatial analysis showed that cancer cases in Hospital USM represented a clustered pattern (NNR: 0.549377, Z-score: -8.18, p-value <0.001). (Figure 2).

\subsection{Geographical Accessibility of Thyroid Cancer Cases to Public Hospitals}

Figure 3 shows the mapping of geographical location for all thyroid cancer cases $(n=90)$ from all public hospitals in Kelantan ( $\mathrm{n}=9$ ). Majority of cases were located within $10 \mathrm{~km}$ radius from public hospitals and have good access to these hospitals. Meanwhile, the remaining cases were located beyond $10 \mathrm{~km}$ radius and have poor access to the public hospitals (Figure 3). It was found that 54 cases $(60 \%)$ were located within $10 \mathrm{~km}$ radius from public hospitals. Out of 54 cases, 31 cases were found to overlap between two hospitals and 1 case overlapped between three hospitals. The remaining 36 cases $(40 \%)$ were situated beyond $10 \mathrm{~km}$ radius from public hospitals, as shown in Figure 4.

\subsection{Types of Thyroid Carcinoma}

Based on histopathological diagnosis, most of the cases were papillary $(71 \%)$, followed by follicular $(17 \%)$, anaplastic $(10 \%)$ and poorly differentiated carcinoma (2\%), as illustrated in Figure 5.

\subsection{Thyroid Cancer Cases According to Districts}

The number of cases were reported according to districts. A total of 9 districts from Kelantan state and 6 districts from Terengganu state were involved in this study, as shown in Table 1.

\section{Discussion}

The spatial analysis revealed that distribution of thyroid cancer cases were spatially clustered and most of the cases were concentrated at the northern part of Kelantan, where the state capital city, Kota Bharu was located. Similarly, previous local study also reported most of the cases were found in Kota Bharu district (Othman et al., 2018). 


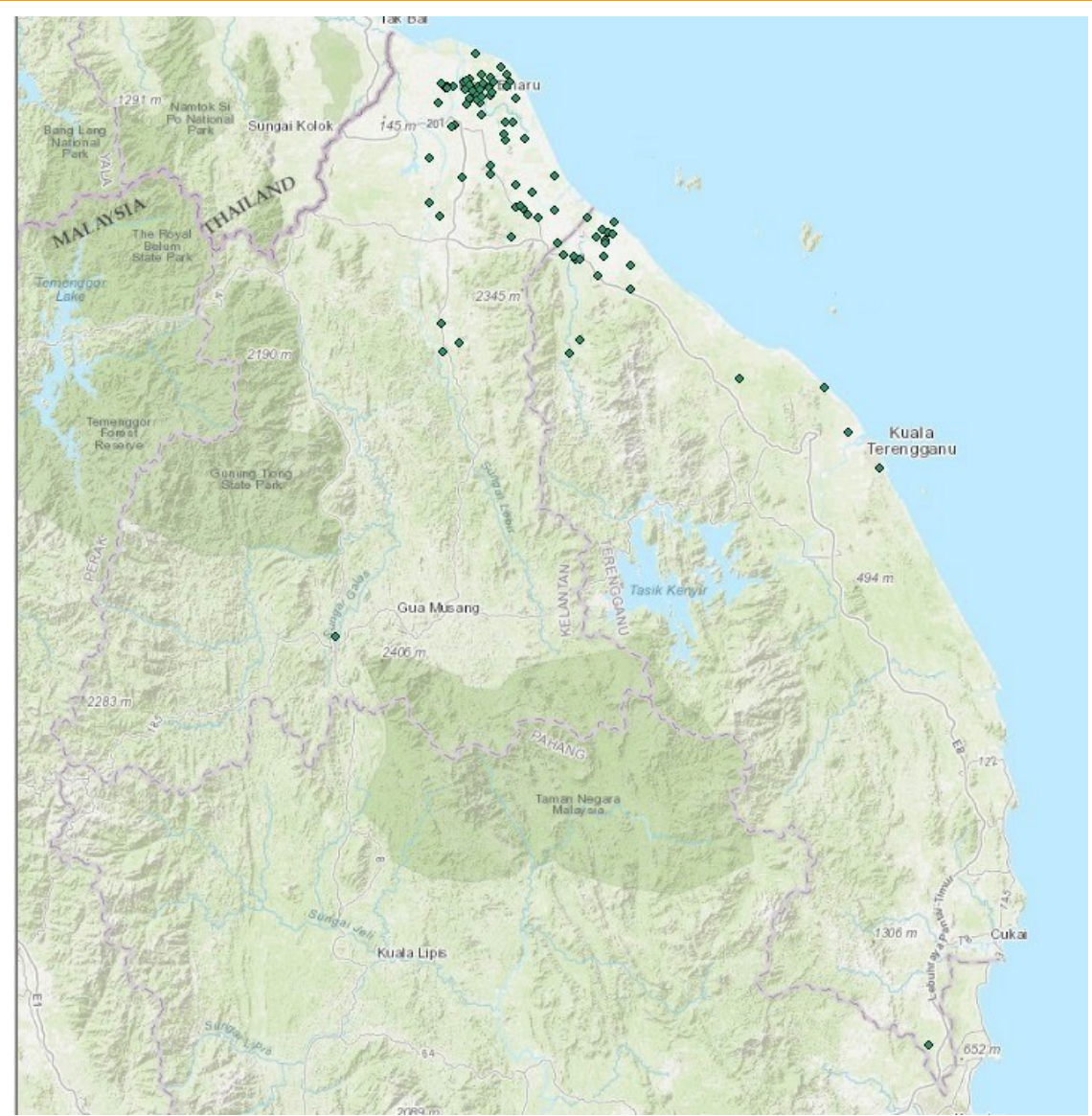

Figure 1: Geographical distribution of thyroid cancer cases

\section{Average Nearest Neighbor Summary}

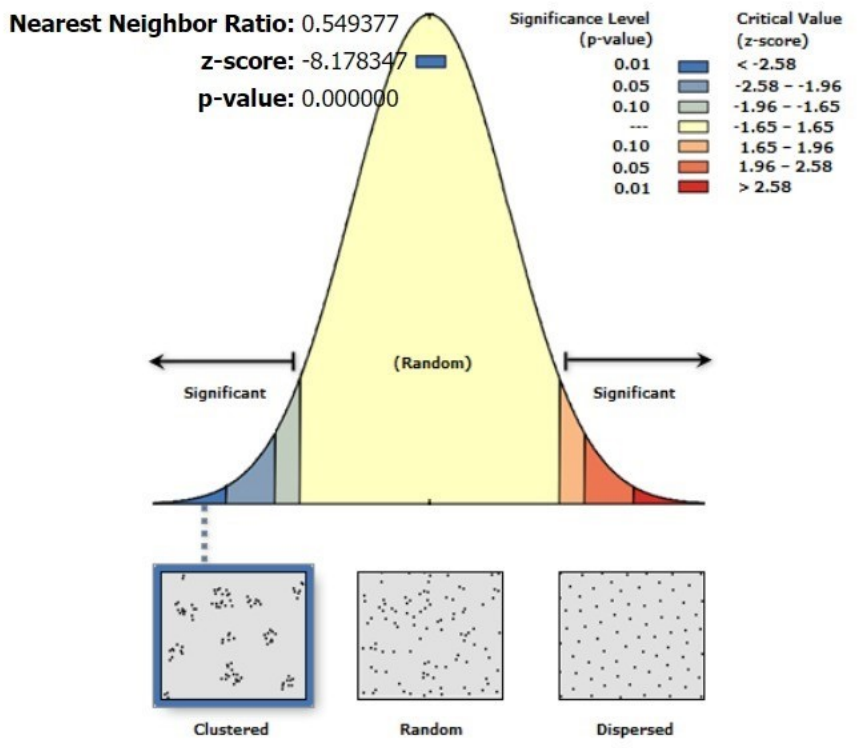

Given the $z$-score of -8.18 , there is a less than $1 \%$ likelihood that this clustered pattern could be the result of random chance.

Figure 2: Spatial distribution of thyroid cancer incidences 


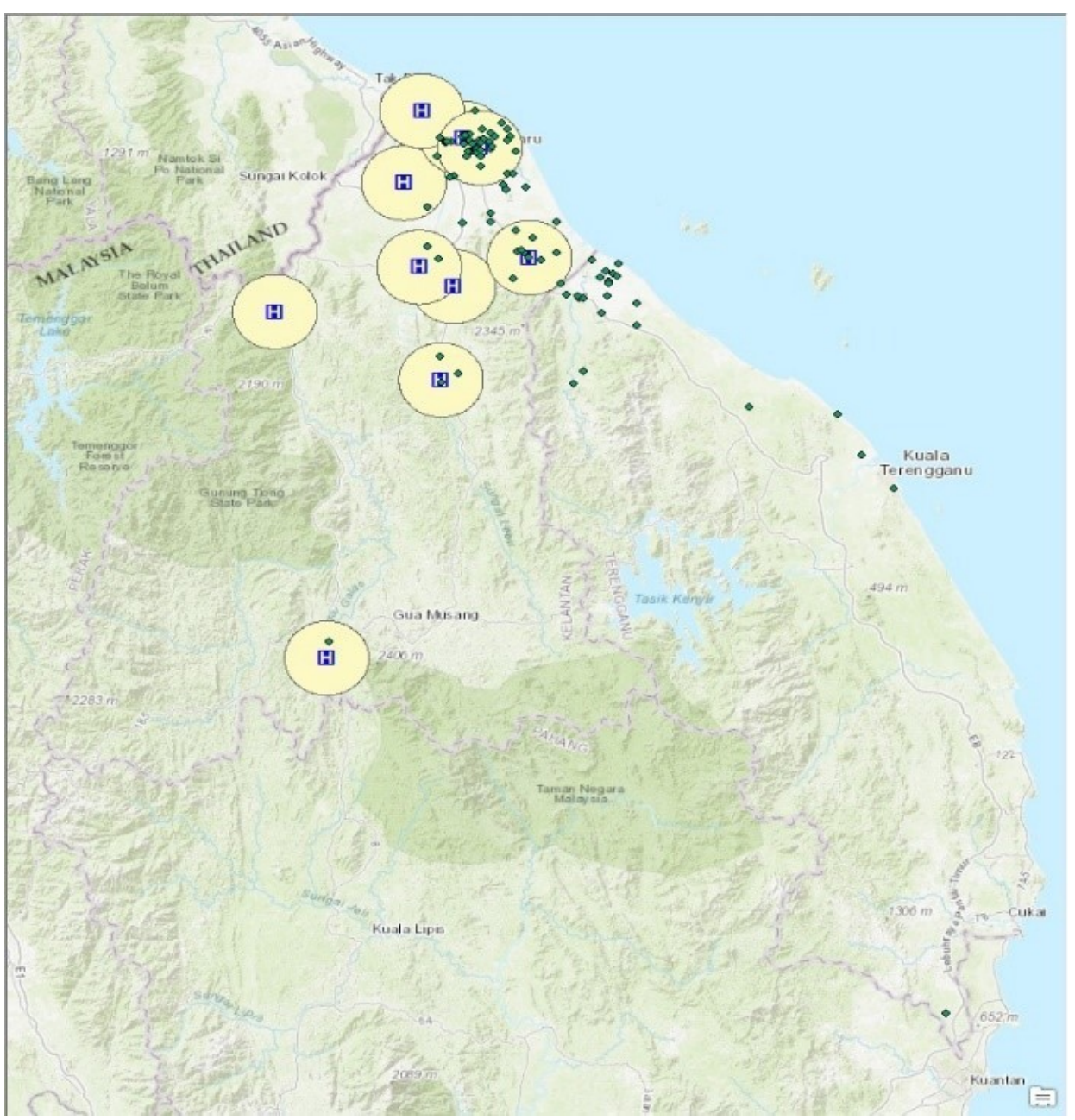

Figure 3: Geographical distribution of all thyroid cancer cases within and beyond $10 \mathrm{~km}$ radius from public hospitals

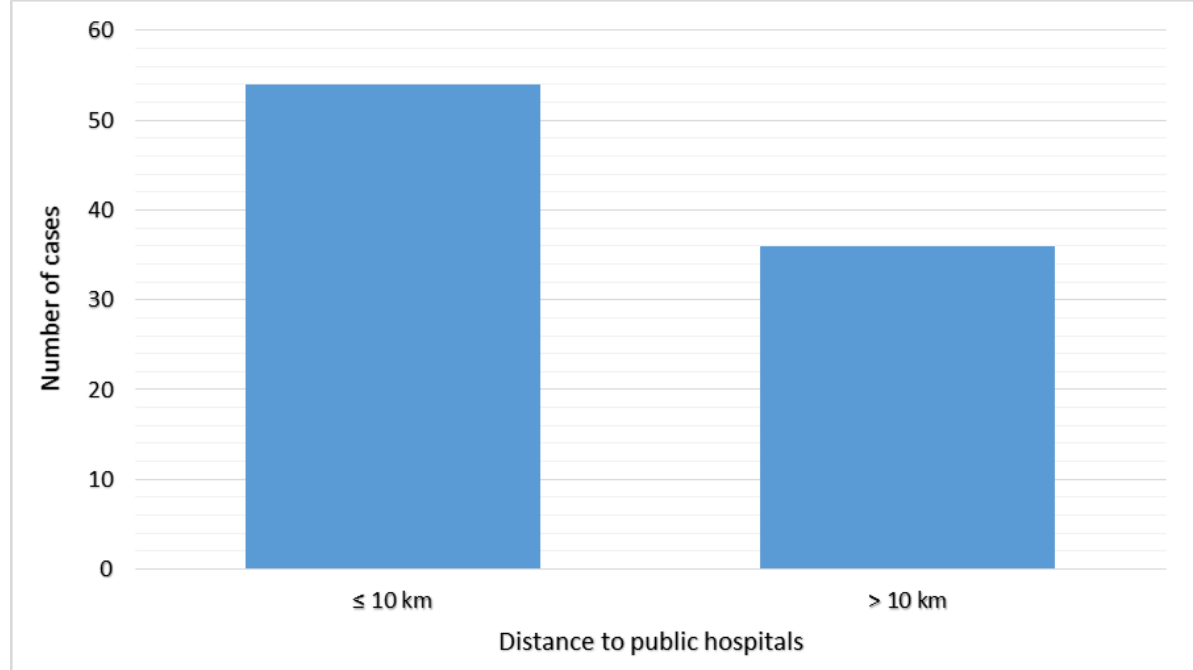

Figure 4: Number of thyroid cancer cases according to the distance with radius of $\leq 10 \mathrm{~km}$ and $>10 \mathrm{~km}$ to public hospitals 


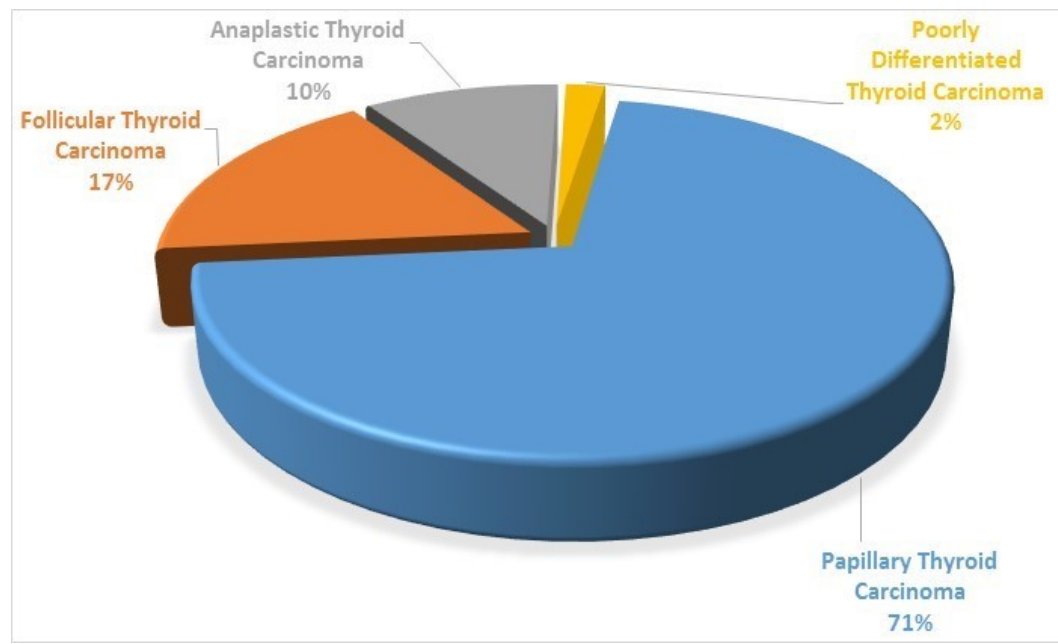

Figure 5: Percentage of thyroid cancer cases according to tumour types in Hospital USM from year 2013 to 2020

Table 1: Number of thyroid cancer cases according to all districts in Kelantan and few districts in Terengganu

\begin{tabular}{|l|l|}
\hline Districts & Number of Cases \\
\hline Kota Bharu & 30 \\
\hline Bachok & 12 \\
\hline Pasir Mas & 2 \\
\hline Pasir Puteh & 11 \\
\hline Machang & 1 \\
\hline Tumpat & 5 \\
\hline Tanah Merah & 1 \\
\hline Kuala Krai & 3 \\
\hline Gua Musang & 1 \\
\hline Besut & 19 \\
\hline Kuala Terengganu & 1 \\
\hline Kemaman & 1 \\
\hline Setiu & 1 \\
\hline Kuala Nerus & 1 \\
\hline Marang & 1 \\
\hline Total & 90 \\
\hline
\end{tabular}

Furthermore, other cancer also found to be distributed at major town centres as reported by two local studies in Penang state (Samat et al., 2010, 2013). This probably due to the highest concentration of Malay population in this area, which made up the largest ethnic group in Kelantan. According to Malaysian National Cancer Registry, Malay ethnic are more likely to have thyroid cancers with an age-standardised incidence rates of 3.8 per 100,000 population (Azizah et al., 2019). Similarly, our data also suggested that Malay ethnic were more predominant in thyroid carcinoma cases observed. This is line with previous study which reported that the Malays (Abdullah, 2002) and the Ibans (Htwe et al., 2009) have a higher tendency to have thyroid cancer compared to other races.

Apart from that, risk factors associated with thyroid carcinomas might be one of explanatory factors. Known risk factors for thyroid cancer are radiation exposure (Cardis and Hatch, 2011), genetics (Soares et al., 2011 and Przybylik-Mazurek et al., 2011), obesity (Kitahara, 2011) and iodine deficiency (Liu et al., 2009, Dal Maso et al., 2009 and Franceschi, 1998). Previous study showed that Kelantan population have chronic iodine deficiency, with the overall urinary iodine excretion is lower than normal at $57 \mu$ /day (Mafauzy et al., 1995) . In addition, it was found that those who live in districts near coastlines (Bachok, Kota Bharu, Pasir Puteh, and Tumpat) had higher frequency of thyroid cancers and are expected to be less-iodine deficient than those in districts located far inland (Othman et al., 2018). Since the districts near the coastlines were located at the northern part of Kelantan, we hypothesised that iodine deficiency is one of the risk factors which may explain the high concentration and clustering of cases observed. Papillary thyroid carcinomas were more frequent among other 
cancers associated with iodine deficiency (Othman et al., 2018). Our data suggested that papillary thyroid carcinoma is the most common histological subtype which accounted for 64 cases (71\%) out of total cases. The similar pattern were also reported in other studies (Htwe et al., 2009 and Othman et al., 2018).

In addition, genetics might play a significant role. A previous study was done on goitrous patients in Kelantan, about $22.7 \%$ Chronic Multi-Nodular Goitre (MNG) or nodular hyperplasia expressed RET protein, the protein known to be involved in thyroid cancer (Omar and Othman, 2003). The cause of MNG is chronic iodine deficiency. RET gene mutation is associated with thyroid cancer (Nikiforov and Nikiforova, 2011). Possibly, this gene mutation occur more frequent among populations in the northern part of the state due to higher exposure of carcinogenic environmental factors. It is known that more factories were located in the northern region of the state. Furthermore, greater number of health facilities available (Samat et al., 2010) and population's ease of access to health facilities might play significant roles. In northern part of the state, there were 6 public hospitals in ratio to a total of 1492.4 populations as compared to southern part with only 4 public hospitals in ratio to 467.3 populations. This high hospital to population ratio in the northern region of the state indicated ease of access to health facilities, which might explain our finding. As reported by Dangisso et al, (2015), higher case notification rates were observed in locations where people have good access to treatment facilities (Dangisso et al., 2015). Apart from that, registration of cases possibly more complete in these areas as compared to other part of the state and faster or more refined diagnostic technique might also be one of the potential factors (Ahmadi et al., 2018). Being a referral centre, Hospital Universiti Sains Malaysia (HUSM) is located in the northern region of the state. All cases of thyroid cancers seen in other hospitals in Kelantan and adjacent states were referred to HUSM for futher management. Hence, the high number of cases registration in this hospital might contribute to high cases concentration and clustering pattern seen in the northern region of the state. However, we could not identify the high-risk areas as there were no statistically significant hotspot areas reported in this study.

In terms of accessibility of cases to public hospitals, the geographic accessibility was measured as: $\quad 0-10 \mathrm{~km}=$ good geographical access; and $>10 \mathrm{~km}=$ poor geographical access (Kuupiel et al., 2019). Majority of patients (60\%) had good geographic access to the public hospitals as they were located within $10 \mathrm{~km}$ of radius from public hospitals. Among these patients, most of them resided in the northern part of Kelantan. Hence, we postulated that the greater availability of public hospitals in this region as compared to the southern part might be an explanatory factor. Since the good geographical access areas were located in the northern region, this give an indication that the distribution of public hospitals in this region are good. Patients who lived in these areas were more likely to utilize the health facilities as they were located nearby in comparison to those lived far away (Mizen et al., 2015). This will increase the chance of getting early diagnosis and treatment for the cancer.

Furthermore, it was noted that $40 \%$ of patients had poor geographic access to public hospitals. However, most of these patients resided in the neighbouring state, where they came to our hospital as referral cases for further management of the diseases. This finding implied that these patients had to travel far to seek for health care services. Travelling more than $10 \mathrm{~km}$ from resident area to health facilities was reported to cause delay in receiving treatment (Yimer et al., 2005) and associated with higher health risks or unfavourable outcomes (Becher et al., 2004). This might be due to longer travel time required to reach the nearest health facilities for treatment (Ursulica, 2016). Several studies demonstrated that time required to travel were related with delay in returning for treatment (Finnie et al., 2011 and Ross et al., 2015). In addition, a local study showed that patients who presented with late stage of cancer were also poor, not educated and from rural areas (Leong et al., 2007). Furthermore, other studies also showed that poor geographical access and socio-economic factors (SES) cause late stage detection of cancer diagnosis (Lyons, 2004 and Rushton et al., 2006). However, in this study, we do not correlate the sociodemographic factors and educational background of the populations with geographic accessibility. Hence, further study is recommended to be conducted to find the correlation between these factors.

\section{Conclusion}

From the findings, this study proved that the spatial distribution of thyroid cancer cases were clustered with most of the cases were concentrated at the northern part of Kelantan, where the state capital city, Kota Bharu was located. Presence of more risk factors such as iodine deficiency, genetic mutations and exposure to carcinogenic environmental factors in the northern region might be the cause. Considering the chronic iodine deficiency in 
Kelantan populations, more iodized salt supplementation might be needed in the diet of population and more awareness programs regarding thyroid cancer risk and factors should be conducted in this region.

Furthermore, majority of the cases have good geographical access to the public hospitals where these cases are also located in the northern region of the state. These findings give an indication that the distribution of public hospitals in the northern part of Kelantan are good. Hence, giving the idea that more health care services should be provided as well as more efforts need to be directed in the locations of poor geographical access in order to minimize the thyroid cancer incidences in Kelantan. In near future, these efforts will help to improve the overall health population in Kelantan.

\section{Limitation of Study}

This study mapped the confirmed cases of thyroid carcinomas in Hospital USM and evaluate their spatial distribution. Hence, it could not properly explain the spatial distribution of the disease in Kelantan state as a whole.

\section{Acknowledgment}

Author would like to thank Hospital Universiti Sains Malaysia and School of Medical Sciences, Universiti Sains Malaysia for the support given.

\section{References}

Abdullah, M., 2002, Thyroid Cancer: The Kuala Lumpur Experience. ANZ J Surg, Vol. 72(9), 660-664.

Ahmadi, A., Ramazani, R., Rezagholi, T. and Yavari, P., 2018, Incidence Pattern and Spatial Analysis of Breast Cancer in Iranian Women: Geographical Information System Applications. East Mediterr Health J. Vol. 24(4), 360-367.

Ahn, H. S., Kim, H. J. and Welch, H. G., 2014, Korea's Thyroid-Cancer "Epidemic"--Screening and Overdiagnosis. $N$ Engl. J, Med., Vol. 371(19), 1765-1767.

Azizah, A. M., Hashimah, B., Nirmal, K., Siti Zubaidah, A. R., Puteri, N. A., Nabihah, A., Sukumaran, R., Balqis, B., Nadia, S. M. R., Sharifah, S. S. S., Rahayu, O., Nur Alham, O. and Azlina, A. A., 2019, Malaysian National Cancer Registry Report 2012-2016, National Cancer Registry, 5: 19, 1-116.

Becher, H., Muller, O., Jahn, A., Gbangou, A., Kynast-Wolf, G. and Kouyate, B., 2004, Risk Factors of Infant and Child Mortality in Rural Burkina Faso. Bull World Health Organ, Vol. 82(4),265-73
Busco, S., Giorgi Rossi, P., Sperduti, I., Pezzotti, P., Buzzoni, C. and Pannozzo, F., 2013, Increased Incidence of Thyroid Cancer in Latina, Italy: A Possible Role of Detection of Subclinical Disease. Cancer Epidemiol. Vol. 37(3), 262-269.

Cardis, E. and Hatch, M., 2011, The Chernobyl Accident-An Epidemiological Perspective. Clinical Oncology. Vol. 23(4), 251-260.

Chen, A. Y., Jemal, A. and Ward, E. M., 2009, Increasing Incidence of Differentiated Thyroid Cancer in the United States, 1988-2005. Cancer, Vol. 115(16)3801-3807.

Colonna, M., Uhry, Z., Guizard, A., Delafosse., P., Schvartz, C., Belot, A., Grosclaude, P. and the FRANCIM network 2015, Recent Trends in Incidence, Geographical Distribution, and Survival of Papillary Thyroid Cancer in France. Cancer Epidemiol, Vol. 39(4),511-518.

Dal Maso, L., Bosetti, C., La Vecchia, C., Franceschi, S., 2009, Risk factors for thyroid cancer: an epidemiological review focused on nutritional factors. Cancer Causes Control. 20(1):75-86.

Dangisso, M. H., Datiko, D. G. and Lindtjorn, B., 2015, Accessibility to Tuberculosis Control Services and Tuberculosis Programme Performance in Southern Ethiopia. Glob Health Action, Vol. 8(1), 1-10.

Davies, L. and Welch, H. G., 2006, Increasing Incidence of Thyroid Cancer in the United States, 1973-2002. JAMA, Vol. 295(18), 21642167.

Davies, L. and Welch, H. G., 2014, Current Thyroid Cancer Trends in the United States. JAMA Otolaryngol Head Neck Surg, Vol. 140(4),317322.

Du, L. B., Li, H. Z., Wang, X. H., Zhu, C., Liu, Q. C., Li, Q. L., Li, X. Q., Shen, Y. Z., Zhang, X. P., Ying, J. W., Yu, C. D. and Mao, W. M., 2014, Analysis Of Cancer Incidence in Zhejiang Cancer Registry in China during 2000 to 2009, Asian Pac J Cancer Prev, Vol.15(14), 58395843.

Enewold, L., Zhu, K., Ron, E., Marrogi, A.J., Stojadinovic, A., Peoples, G.E., et al, 2009, Rising thyroid cancer incidence in the United States by demographic and tumor characteristics, 1980-2005. Cancer Epidemiol Biomark Prev. 18(3):784-91

Finnie, R. K., Khoza, L. B., van den Borne, B., Mabunda, T., Abotchie, P. and Mullen, P. D., 2011, Factors Associated with Patient and Health Care System Delay in Diagnosis and Treatment for TB in Sub-Saharan African Countries with High Burdens of TB and HIV. Tropical Med Int Health, Vol. 16(4), 394-411. 
Franceschi, S., 1998, Iodine Intake and Thyroid Carcinoma-A Potential Risk Factor. Exp. Clin. Endocrinol Diabetes, Vol. 106(3), 38-44

Franceschi, S. and Vaccarella, S., 2015, Thyroid Cancer: An Epidemic of Disease or an Epidemic of Diagnosis?. International Journal of Cancer, Vol. 136(11), 2738-2739.

Globocan, 2020, Available from: https://gco.iarc.fr/today/data/factsheets/cancers/32-Thyroid-factsheet.pdf. (Retrieved 10 March 2021).

Goodarzi, E., Moslem, A., Feizhadad, H., Jarrahi, A.M., Adineh, H.A., Sohrabivafa, M. and Khazaei, Z., 2019, Epidemiology, Incidence and the World: An Ecology Study in 2018. Adv Hum Biol, Vol. 9(2), 162-167.

Hanley, J. P., Jackson, E., Morrissey, L. A., Rizzo, D. M., Sprague, B. L., Sarkar, I. N. and Carr, E. F., 2015, Geospatial and Temporal Analysis of Thyroid Cancer Incidence in a Rural Population. Thyroid: Official Journal of the American Thyroid Association, Vol. 25(7), 812-822.

Higgs, G., Smith, D. and Gould, M., 2005, Findings from a Survey on GIS Use in the UK National Health Service. Organizational Challenges and Opportunities, Vol. 72, 105-117.

Horner, M. J., Ries, L. A. G., Krapcho, M., Neyman, N., Aminou, R., Howlader, N., Altekruse, S. F., Feuer, E. J., Huang, L., Mariotto, A., Miller, B. A., Lewis. D. R., Eisner, M. P., Stinchcomb, D. G., Edwards, B. K., 2009, SEER Cancer Statistics Review, 19752006. Bethesda: National Cancer Institute; 23:143-56.

Htwe, T. T., Hamdi, M. M., Swethadri, G. K., Wong, J. O., Soe, M. M., Abdullah, M. S., 2009, Incidence of Thyroid Malignancy among Goitrous Thyroid Lesions from the Sarawak General Hospital 2000-2004. Singapore Med J, Vol. 50(7), 724-728.

Jung, K. W., Won, Y. J., Kong, H. J., Oh, C. M., Cho, H., Lee, D. H. and Lee, K. H., 2015, Cancer Statistics in Korea: Incidence, Mortality, Survival, and Prevalence in 2012. Cancer Research and Treatment, Vol. 47(2), 127-141.

Kilfoy, B. A., Zheng, T., Holford, T. R., Han, X., Ward, M. H.., Sjodin, A., Zhang, Y., Bai, Y., Zhu, C., Guo, G. L., Rothman, N. and Zhang, Y. W., 2009, International Patterns and Trends in Thyroid Cancer Incidence, 1973-2002. Cancer Causes Control., Vol. 20(5):525-531.

Kitahara, C. M., Platz, E. A., Freeman, L. E., Hsing, A. W., Linet, M. S., Park, Y., Schairer, C., Schatzkin, A., Shikany, J. M. and Berrington de Gonzalez, A., 2011, Obesity and Thyroid Cancer Risk among U.S. Men and Women: A Pooled Analysis of Five Prospective Studies. Cancer
Epidemiol Biomarkers Prev., Vol. 20(3), 464472.

Kuupiel, D., Adu, K. M., Apiribu, F., Bawontuo, V., Adogboba, D. A., Ali, K.T. and Thompson, T. M., 2019, Geographic Accessibility to Public Health Facilities Providing Tuberculosis Testing Services at Point-of-Care in the Upper East Region, Ghana. BMC Public Health, Vol. 19(1), 1-12

La Vecchia, C., Malvezzi, M., Bosetti, C., Garavello., W., Bertuccio, P., Levi, F. and Negri, E., 2015, Thyroid Cancer Mortality and Incidence: A Global Overview. International Journal of Cancer. Vol. 136(9), 2187-2195.

Levine, R. S., Yorita, K. L., Walsh, M. C., Reynolds, M. G., 2009, A Method for Statistically Comparing Spatial Distribution Maps. International Journal of Health Geographics, Vol.8(1), http://www.ijhealthgeographics.com/content/8/.(Retrieved 10 March 2021).

Leong, B. D., Chuah, J. A., Kumar, V. M. and Yip, C. H., 2007, Breast Cancer in Sabah, Malaysia: a Two Year Prospective Study. Asian Pacific Journal of Cancer Prevention:APJCP, Vol. 8(4), 525-529.

Liu, S., Semenciw, R., Ugnat, M. and Mao, Y., 2001, Increasing Thyroid Cancer Incidence in Canada, 1970-1996: Time Trends and AgePeriod-Cohort Effects. $\mathrm{Br} J$ Cancer., Vol. 85(9):1335-1339.

Liu, X, H., Chen, G, G., Vlantis, A. C. and van Hasselt, C. A., 2009, Iodine Mediated Mechanisms and Thyroid Carcinoma. Crit. Rev. Clin Lab Sci., Vol. 46(5-6), 302-318.

Lyons, M. A., 2004, Psychosocial Impact of Cancer in Low Income Rural/Urban Women: Phase 1. Online Journal of Rural Nursing and Health Care, Vol. 4(1). http://www.rno.org/journa1/issues/vol4/issue1/Lyons_article.htm (retrieved 10 March 2021).

Mafauzy, M., Mohamad, W. B, Anum, M. Y. and Musalmah, M., 1995, Urinary Iodine Excretion in the Northeast of Peninsular Malaysia. Southeast Asian J Trop Med Public Health, Vol. 26(1), 138-142.

Moore, D. A. and Carpenter, T. E., 1999, Spatial Analytical Methods and Geographic Information Systems: Use in Health Research and Epidemiology. Epidemiologic Review, Vol. 21(2), 143-161.

Mizen, A., Fry, R., Grinnell, D. and Rodgers, S. E., 2015, Quantifying the Error Associated with Alternative GIS-based Techniques to Measure Access to Health Care Services. AIMS Public Heal., Vol. 2(4), 746-761. 
Musa, G. J., Chiang, P. H., Sylk, T., Bavley, R., Keating, W., Lakew, B., Tsou, H. C. and Hoven, W. C., 2013, Use of GIS Mapping as a Public Health Tool-from Cholera to Cancer. Health Serv Insights, Vol. 6, 111-116.

Nikiforov, Y. E. and Nikiforova, M. N., 2011, Molecular Genetics and Diagnosis of Thyroid Cancer. Nature Reviews Endocrinology, Vol. 7(10), 569-580.

Omar, E. and Othman, N., 2003, Immunohistochemical localization of RET rearrangements in a Malaysian papillary thyroid carcinoma population. The Medical Journal of Malaysia., Vol. 58(3), 461-462.

Othman, N. H., Nor, Z. M. and Biswal, B. M., 2008, Is Kelantan Joining the Global Cancer Epidemic?-Experience from Hospital Universiti Sains Malaysia; 1987-2007. Asian Pac J Cancer Prev, Vol. 9(3), 473-478.

Othman, N. H., Ghani, N. N. A. and Mohd, N. Z., 2018, Clinico-pathological Characteristics and Survival Analysis of 300 Thyroid Cancer Cases in One Referral Hospital in Kelantan, Malaysia: A 10-year Study. Asian Pacific Journal of Cancer Care, Vol. 3(3), DOI:10.31557/apjcc.2018.3.3.53.

Przybylik-Mazurek, E., Pach, D., Kuzniarz-Rymarz, S., Tracz-Bujnowicz, M., Szafraniec, K., Skalniak, A., Sowa-Staszczak, A., PiwonskaSolska, B. and Hubalewska-Dydejczyk, A., 2011, The Positive Family History of Thyroid Disease as a Risk Factor for Differentiated Thyroid Carcinoma. Pol Arch Med Wewn, Vol. 121(12), 441-446.

Reynolds, R. M., Weir, J., Stockton, D. L., Brewster, D. H., Sandeep, T. C. and Strachan, M. W. J., 2005, Changing Trends in Incidence and Mortality of Thyroid Cancer in Scotland. Clin Endocrinol. Vol. 62(2), 156-162.

Ross, J. M., Cattamanchi, A., Miller, C. R., Tatem, A. J., Katamba, A., Haguma, P., Handley, M. A. and David, J. L., 2015, Investigating Barriers to Tuberculosis Evaluation in Uganda Using Geographic Information Systems. Am J Trop Med Hyg, Vol. 93(4), 733-738.

Rushton, G., Armstrong, M., Gittler, J., Greene, B., Pavlik, C., West, M. and Zimmerman, D. L., 2006, Geocoding in Cancer Research: A Review. American Journal of Preventive Medicine, Vol. 30(2S), S16-S24.
Samat, N., Shattar, A. K. A., Sulaiman, Y., Ab Manan, A. and Weng, C. N., 2013, Investigating Geographic Distribution of Colorectal Cancer Cases: An Example from Penang State, Malaysia. Asian Soc. Sci, Vol. 9, 38-46.

Samat, N., Jambi, D., Musa, N. S., Shatar, A. K. A., Ab Manan, A. and Sulaiman, Y., 2010, Using A Geographic Information System (GIS) in Evaluating the Accessibility of Health Facilities for Breast Cancer Patients in Penang State, Malaysia. Kajian Malaysia, Vol. 28 (1), 103122.

Soares, P., Lima, J., Preto, A., Castro, P., Vinagre, J., Celestino, R., Couto, J. P., Prazeres, H., Eloy, C., Máximo, V. and Sobrinho-Simões, M., 2011, Genetic Alterations in Poorly Differentiated and Undifferentiated Thyroid Carcinomas. Current Genomics, Vol.12(8), 609-617.

Tsai, P. J., 2012, Application of Moran's Test with an Empirical Bayesian Rate to Leading Health Care Problems in Taiwan in a 7-Year Period (2002-2008). Glob J. Health Sci., Vol. 4, 63-77.

Scott, D., Curtis, B. and Twumasi, F. O., 2002, Towards the Creation of a Health Information System for Cancer in KwaZulu-Natal, South Africa. Health Place, Vol. 8, 237-249.

Ursulica, T. E., 2016, The Relationship between Health Care Needs and Accessibility to Health Care Services in Botosani County- Romania. Procedia Environmental Sciences, Vol. 32, 300310.

Wang, F., McLafferty, S., Escamilla, V. and Luo, L., 2008, Late-Stage Breast Cancer Diagnosis and Health Care access in Illinois. The Professional Geographer, Vol. 60(1), 54-69.

Xie, W. C., Chan, M. H., Mak, K. C., Chan, W. T. and He, M., 2012, Trends in the Incidence of 15 Common Cancers in Hong Kong, 1983-2008. Asian Pac J Cancer Prev, Vol.13(8),3911-3916.

Xie, S. H., Chen, J., Zhang, B., Wang, F., Li, S. S., Xie, C. H., Tse, L. A. and Cheng, J. Q., 2014, Time Trends and Age-Period-Cohort Analyses on Incidence Rates of Thyroid Cancer in Shanghai and Hong Kong. BMC Cancer, Vol. 14, doi: 10.1186/1471-2407-14-975.

Yimer, S., Bjune, G. and Alene, G., 2005, Diagnostic and Treatment Delay among Pulmonary Tuberculosis Patients in Ethiopia: A Cross Sectional Study. BMC Infect Dis, Vol. 5(1), 1-17, DOI:10.1186/1471-2334-5-112. 